\title{
Research on Creation Method of Illustration and Picture Books and Its Psychological Effect on Particular Groups*
}

\author{
Haiyan Xie \\ College of Art and Design \\ Zhuhai College of Jilin University \\ Zhuhai, China 519041
}

\begin{abstract}
Illustration and picture books have been recognized by more and more parents, schools, education and training institutions with the continuous development of education in China and the promotion of people's educational concepts. It achieved the function of cognition, indoctrination and aesthetic education through design elements of visual pictures, simple texts, and unique colors. The unique visual features of the picture books can make readers pay more attention to the books, immerse themselves in the content of illustration and picture book to inspire their resonance, and guide and develop their minds correctly. They even can help the guidance of correct personality and emotion recognition on some specific groups.
\end{abstract}

Keywords-picture books; creation; specific; psychology

\section{INTRODUCTION}

Education issues have always been one of the highest concerns of Chinese people. At the beginning of the formation of Chinese culture, there were educational concepts that conformed to the characteristics of each era. The poetry and painting as well as being educated and reasonable have always been some basis of Chinese education, that is to say, Moral education and emotional education have always run through China's education since ancient times. The picture books, as a form of books as well as an expression of artistic creation, play an important role in moral education, emotional education, even psychological education and other teaching methods.

\section{THE IMPORTANCE OF ILLUSTRATION AND PICTURE BOOK CREATION}

\section{A. The Cultivation of Innovation}

With the progress of the times, the Chinese economy has developed at an alarming rate these years, and people's living standards and quality have also rapidly increased. People's concern in life is not just about food and clothing,

*Fund Project: Research on creation method of illustration and picture book and its psychological effect on particular groups, 2016GXJK202, key platforms and major projects of Education Bureau of Guangdong Province in 2016 but "how to eat well" and "how "Eat good-looking" spiritual and cultural issues, then the ensuing education problems have also changed with changes in people's concerns. With the rapid development of economy, some new and excellent educational ideas abroad have also been continuously flooded into China and understood by Chinese people.

In foreign education, the cultivation of innovation and creativity has been carried through from early childhood to higher education. The competition in today's society is not so much the competition of talents as it is the competition of human creativity. The innovation ability is the soul of the national progress and the core of economic competition. The cultivation of innovation ability is particularly important in the modern era of highly competitive information. The General Secretary Xi also emphasized in his speech that development is the top priority, talent is the primary resource, and innovation is the primary driving force. In current education in China, apart from moral and aesthetic education, the most important thing is the cultivation of students' innovative abilities. The cultivation of innovative ability can be better exercised in this type of illustration and picture books reading and creation. In the process of illustration and picture reading, readers can obtain information through vision, feeling, hearing and other means. There are also some three-dimensional books that can attract readers' attention and resonance, thus allowing readers to think in all aspects during the process of obtaining information and get new creations in other fields eventually.

\section{B. The Cultivation of Readers' Correct Moral Values and Values Is the Most Direct Way}

Morality is the systematic understanding and perspectives of people on the relations with themselves, others and the world. It belongs to the category of social ethics. The moral concept in Chinese traditional philosophy mainly refers to the orthodox traditional morality with Confucianism as legitimacy. However, there are also differences of morality concepts in different countries, different nations, and different groups. There should be correct standards or norms on the differences. The ideal pursuing of "Self-achievement, but also helping others" that Chinese predecessors are concerned with is actually a 
valuable presupposition. Without the presupposition of such values, the existence and activities of people and everything lose their meanings. ${ }^{[1]}$

\section{It Has an Important Psychological Effect on Readers}

The basic meaning of mental health refers to all aspects and active processes of mentality being in a good or normal state. The ideal state of mental health refers to the state maintaining a perfect personality, normal intelligence, correct cognition, appropriate emotions, reasonable will, positive attitude, appropriate behavior and good adaptation. Mental health has different meanings from different perspectives and measurement criteria are also different. The main groups of picture books are teenagers. Although the psychological characteristics of the group have not yet reached the control ability of mental health, in their study and life, the cultivation and persuasion of mental health is particularly important in the process. The creation of picture book should also combine with the importance, patterns and methods creation of the mental health. It also should guide the readers to adapt to the changing environment, gradually improve their personality characteristics, and understand the world and recognize them in the process of character development as well as treat external influences correctly in order to enable readers to maintain balance and coordination on psychology and form a good psychological influence on the target groups eventually.

\section{RESEARCH ON THE METHOD OF ILLUSTRATION AND PICTURE BOOK CREATION}

\section{A. The Primary Task of Picture Book Creation Is the Study of the Psychological Characteristics of Target Readers}

For a design work, the analysis and research on the needs of people or groups is a very necessary. The ultimate purpose of the process is to make the information created by various methods accurate, effective, and targeted. In the picture book creation, the research and analysis of the psychological characteristics of the target readers is more important. Through the analysis of the conclusions, creators can grasp the scale of creation, for example: the psychological characteristics of the young people are gradually maturing, but their views on things are not as mature as adults, and they have their own understanding of things. It cannot take measures as easy as the creation of children's picture books, and some clever techniques and attractive contents in the process of picture book creation are needed. The attraction of method and content makes the picture book attract the attention of the group to attract the attention of this group, make them resonate with the text and illustrations on the picture book, and finally get correct psychological counseling. The excessively complicated text and image display is not suitable for infants' reading because the population characteristics of this age are that their reading ability for texts and pictures is limited and they have more interests on color and texture, so words should not be too much. The choice of the methods and the solution to problems in the creative process requires the designers to carry out positioning and research on accurate psychological feature of the target groups.

\section{B. Good Theme Is the Key to a Successful Picture Book Accepted by Readers}

The theme usually refers to those life events or vital phenomena collected in works through collection, choice, and refinement. Theme is also one of the elements of the literary content. For a television work or a novel, a good theme is also the key to the acceptance of literary and artistic works. In the picture book creation, the choice of a good theme is also an important link for readers to accept a picture book.

\section{Modeling Languages}

An artistic work refers to the education activity using aesthetics and the laws of creating beauty to influence the senses and psychology of educatee and cultivate students' keen perception, rich imagination, direct insight and creativity. Since Confucius established Confucianism education in China, aesthetic education has been advocated. Aesthetic education is also the first education direction in education in China and even the world. It is better than any preaching for guide educated people to have a good education of aesthetic and morality. The aesthetic education even is a way superior to legal sanction for educatee to obtain good quality and good behavior.

In the creation of picture books, it is required that the modeling language to be healthy and positive. In the shape of form, people can choose their own specific expressions according to the acceptance levels of different ages, such as point-based molding, line modeling and surface modeling.

\section{Accurate Design of Colors}

In visual communication, the first thing that comes into sight is color. Human has a vision system of healthy eyes that observe everything in the world and feel sunlight. Because of the color attributes, the length of waves determines the hue attributes of colors. When people see different hue attributes of colors, it will give them different mental experience. For example, red and orange will give people a feeling of warmth and enthusiasm, blue and green will bring people a feeling of cold, and bright yellow will make people feel happy, etc. People can use the psychological features of hue as well as warm and cool colors to make readers feel the rich and colorful life. In the picture book creation, it is necessary to select appropriate colors for different groups. For example, older readers have accurate cognition and even aesthetic appreciation of color, so the expression and design of colors should have accurate aesthetics and cognition in the visual communication design of such reader groups. While the younger readers are indeterminate in colors, it is feasible to increase their sensitivity to color on the premise of ensuring the comfortable picture. That is, the purity of the colors can be higher to stimulate their feeling of color. 


\section{E. The Application of Texture in Picture Book Creation}

Materials and textures have always been a very important means of expression in visual design, and they allow viewers to obtain realistic and accurate design associations. In the creation of picture books, the use of tactile texture expression at the appropriate age can make the readers without profound knowledge of the real world have correct perception of the laws of natural things. The texture is divided into visual texture and tactile texture. Visual texture mainly refers to the characteristics perceived visually, including surface and surface texture of the object and whether it is transparent. The tactile texture mainly refers to the tactile perception including whether the surfaces of objects are smooth or rough, flat or uneven, hard or soft as well as stretchy when being touched. These two kinds of textures have different status in different design forms.

In the creation of illustration and picture books, the form has not been rigidly adhered to the feature of single plane. In the process of creation, some forms of design such as sound and three-dimensional books have been added. The visual texture and tactile texture can be used in the texture expression to reinforce vision and extend thinking for different types of readers so as to train children to learn association and imagination while seeing the information. For example, in the illustrated artwork for babies of 0-2 years old, the rough texture of safe wool as well as smooth texture of plastics and other materials can be added, such as wood having a natural texture, being delicate and distinct, and having a strong affinity. It can make people feel close to nature. The texture of pottery is rough and unpretentious, and it penetrates an aesthetic feeling of recovering original simplicity from head to toe The texture between different types of material can produce extremely rich results. In the case of comparing texture using different materials, the advantages are obvious and the effect is rich and varied. However, if this comparison is not controlled well, it is easy to disorganize the entire design. In the process of using different textures, we must deal with the coordination relationship among the textures. Each kind of material will have different processing technology in the process of its processing, and the final production effect will be very different because of different processing methods. The process makes these groups of people get an understanding of beauty in the real experience of natural things.

\section{THE EFFECT OF ILLUSTRATIONS AND PICTURE BOOKS ON THE GROUPS OF YOUNG CHILDREN}

The excellent creation method of illustration and picture book can have an important influence on the readers. Most of the readers of picture books in the world are young children. It also has an important influence on young children who qualitative aesthetics and values. In the study of this specific group of people, it is not only necessary to establish the important influence of the illustration and picture books, but also to urge the creators of the picture books to make indepth, detailed and earnest researches on the behavioral characteristics, preferences, and psychological needs of the specific groups during the creative process. Only in this way can they choose a specific visual method to create and picture books play an important role. The analysis on the impact of picture books on young children of 4-5 years old is carried out.

\section{A. The Effect of Illustration and Picture Books on the Behavioral Characteristics of Young Children}

The group loves activities, but lacks the rules and techniques in behavioral process. Their teamwork abilities are not strong; they like to imitate, and their language ability is greatly improved compared with the infant stage.

Attention: Groups of this age like all new things such as new books and new toys. Although their short attention spans, they are gradually evolving. The attention span of young children in this age is short, usually 10-15 minutes, and reading is the best way to train this group of readers. In this short picture book reading time, the time may not be long, but the focus is very effective along with more and more illustrations and words, and their focus time will be longer and longer.

Imagination: The imagination of groups in this age is very rich, but among them unconscious imagination has a great advantage and there is a certain exaggeration. They imitate certain things, certain people or animals to a great extent. Therefore, it cannot impose a certain theme or model on for picture book creation, which will hinder the imagination development of children. The imagination of children should be protected and kept away from being influenced by thinking set of adults.

\section{B. The Impact of Illustration and Picture Books on Infant Mentality}

1) It began to develop that enhancing intentional behavior consciousness of the group: Reading picture books can enhance the collective activities awareness of the group, and the time for training them to concentrate on doing something is also longer than before through the reading. For example, in the picture book "Baby Touch and Feel: Animals", there is a page in which the animals' fur texture experience is designed on their bodies. For example, stomachs of the penguins are soft, so artificial materials in this position are set to guide the readers to have tactile experience, and in the process, the group's interests have been actually increased, which allows them to spend more time experiencing and enhances their focuses in group activities. The improvement of focus is accompanied by the process of thinking and it guides the conscious behavior development of readers gradually. 


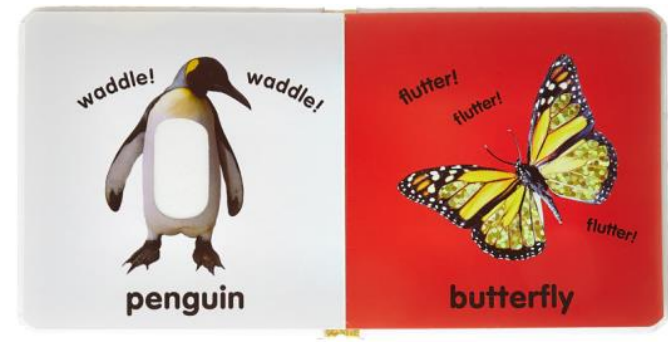

Fig. 1. Picture Book Baby Touch and Feel: Animals

2) It can help young children to control their emotions: American psychologist Goleman said: "EQ (emotional quotient) is the most important viability of mankind". Good emotional management ability is the basis of high EQ, and 3 to 6 years old of children is the best training period. The proportion of groups in this age whose individual behaviors are dominated by emotions is gradually declining. They begin to learn to control their emotions. In the series of picture books entitled "An Interactive Reading Book of Children's emotional management: Thomas \& Friends", a collection of "Toby Doesn't Cry", "Toby Has a Kind Heart", "Thomas Doesn't Be Nervous", "Thomas Doesn't Get Bad", "Thomas Is Not Afraid of the Dark, "Edward Is the Second to None", "Rusty Likes to Laugh", "James Doesn't Be Tart" and other stories, it uses the appropriate language to tell children what to say and do when they encounter these similar problems in order to improve the condition of feeling out of control when the groups cannot meet their wishes. Various methods in the process teach the group how to resolve emotions, express emotions, and manage emotions. There are also explanations for parents to help them analyze the causes of group emotions at this stage and provide methods to deal with them.

3) Enhancing rule consciousness and ability of the group can help them adapt to group living: Although the group are being very polite when they get along with others in group living, for example they can active say "Thank you" and "I'm sorry", know that being praised is something to be happy about as well as being criticized is something unhappy, and they like to be praised and will be unhappy being criticized. However, their rule awareness of concept of right and wrong and etc. is still very vague, while picture book reading can enhance the rule consciousness, allowing them to treat and solve various small problems in the collective life in the right way and mindset, and let them know washing hands before eating, waiting in line for washing hands, and learning to wait for doing things and so on.

4) Helping the group learn to cooperate and share through picture book reading: The ability to cooperate and share is an indispensable and important quality for young children's future development, adaptation to the society, and keeping a foothold in society. For young children, cooperation and sharing refers to actively cooperating with each other, sharing out the work and cooperating with one another, solving problems through consultation, and coordinating relationships in games, learning, and life so as to ensure the smooth progress of activities. At the same time, everyone realizes goals through mutual cooperation and shares the joy of happiness and victory in the process. [2] When the reader group entered the collective life, reading illustration and picture books can enhance their ability to communicate with their peers in life and make them learn to share and feel the joy in it. Readers of this age began to feel jealous and can feel strong anger and frustration. They are unwilling to share with others, including their own articles and even their friends. The guidance of picture book content help them understand and learn how to communicate and collaborate with people.

\section{CONCLUSION}

As an applied discipline, art has always played an important role in life, regardless of its category. As a creative research on a form of artistic expression, the illustration and picture book itself is also of great significance. The meaning requires a solid method of artistic creation and accurate positioning of knowledge in fields such as psychology and behavioristics in order to play a role in the positive innovation, correct emotional values, and healthy psychology of young children. The correct creative methods need to be actively considered from aspects such as composition proportion, features of color, layout of the screen, illustration materials, and innovations in the composition methods. The creative method requires more creative artists to create with a psychological process of childlike innocence and the purpose of young children acquiring knowledge in fun, and only in this way the expected effect can be achieved.

\section{REFERENCES}

[1] Han Zhen. Chinese Values. China Social Sciences Press [M].2016. 韩 震. 中国的价值观.中国社会科学出版社 $[\mathrm{M}] .2016$.

[2] Ji Xiuhong/Zhang Lili. Several Approaches to Develop Children's Ability to Cooperate and Share. New Campus: Learning Edition [J]. 2012. 纪秀红/张莉莉. 幼儿合作与分享能力培养的几点做法.新校 园: 学习版 [J].2012 年.

[3] Zhang Ruhua. Design Color and Its Composition. Tsinghua University Press [M].2016. 张如画. 设计色彩与构成. 清华大学出版 社 $[\mathrm{M}] .2016$. 